IMECE2018-88046

\title{
ENERGY AND EXERGY ANALYSIS OF A BIOMASS BASED CERAMIC PLANT
}

\author{
Diogo Esteves \\ MEtRICs I\&D Centre \\ School of Engineering \\ University of Minho, \\ 4850-058 Guimarães, Portugal
}

\author{
Joana Carvalho \\ MEtRICs I\&D Centre \\ School of Engineering \\ University of Minho, \\ CVR- Centre for Waste Valorization \\ 4850-058 Guimarães, Portugal
}

\author{
Cândida Vilarinho \\ MEtRICs I\&D Centre \\ School of Engineering \\ University of Minho, \\ 4850-058 Guimarães, \\ Portugal
}

\author{
Jorge Araújo \\ CVR- Centre for Waste \\ Valorization \\ 4850-058 Guimarães, \\ Portugal
}

\author{
Manuel Eduardo Ferreira \\ MEtRICs I\&D Centre \\ School of Engineering \\ University of Minho, \\ 4850-058 Guimarães, Portugal
}

\author{
José Teixeira \\ MEtRICs I\&D Centre \\ School of Engineering \\ University of Minho, \\ 4850-058 Guimarães, Portugal
}

\begin{abstract}
The manufacture of relatively low commercial value ceramic products for construction is an energy intensive industry. It is important to improve and optimize the energy equation of the plant operation while simultaneously introducing renewable primary energy sources for the heat supply.

The present paper concerns the analysis of the energy usage in a brick plant. This unit operates continuously on a 3 shift schedule. The overall annual production of five types of bricks is over 62 kton and the main energy consumption unit is the furnace. For this unit, the thermal load is supplied mainly by biomass coupled with fuel oil ( $80 \%-20 \%$ split, respectively) which yield a maximum temperature of $950{ }^{\circ} \mathrm{C}$. The process is controlled by adjusting the air mixing in the kiln. A secondary furnace provides the heat for a rotating dryer for biomass drying which is supplied to the main furnace.

The fuel is a mixture of various sources and its characteristics were determined by means of an elemental analysis, ash content and the measurement of the heat value. Measurements of mass fluxes along with the operating temperature on critical elements of the plant and chemical composition of the flue gases were used to calculate the energy balances to the plant. Because of the diversity of the product mix the production was normalized using the mass/surface area ratio of the various types of bricks. From the results, the energy intensity is $44 \mathrm{~kg}$ of oil equivalent per ton.
\end{abstract}

The exergy analysis of the plant shows that most of the energy degradation occurs in the kiln. The analysis also enabled to assess the influence of the replacing fossil fuel by biomass on the increase of exergy efficiency of the plant.

Keywords: Clay brick; biomass; energy analysis; exergy analysis.

\section{INTRODUCTION}

The manufacturing of structural clay components (mostly tiles and bricks) is a traditional activity in Portugal. Most of the manufacturing plants are located along the coastal strip in the north and center of the territory. Their installed capacity varies between 9,000 and 650,000 ton/year and, on average, they operate below $60 \%$ of their capacity. The rising costs of energy and labor (which account for $50-50 \%$ of the total costs) coupled with reduced demand in the construction sector and the stringent emissions for particulate matter has driven many plants out of business or forced them to relocate to other regions [1].

The drive for cost reduction and emissions control and led many manufacturing plants to switch to biomass for their kilns operation. However there are issues regarding the product quality. Typically, the thermal energy intensity is between 56-74 kgtoe/ton for tiles and 25-50 ktoe/ton for bricks.

A survey of the industry has shown that emissions vary with the fuel source according to Table 1 , which also include 
the Best Available Techniques (BAT). The use of biomass can also be beneficial in terms of emissions $\left(\mathrm{SO}_{2}\right)$ and $\mathrm{CO}_{2}$.

Table 1 - Emissions for different fuel sources $\left(\mathrm{mg} / \mathrm{Nm}^{3}\right)$. [1]

\begin{tabular}{|l|c|c|c|c|}
\hline \multicolumn{1}{|c|}{ Fuel } & Particles & $\mathbf{S O}_{2}$ & NO $_{\mathbf{x}}$ & CO \\
\hline Natural gas & 20 & 15 & 100 & 150 \\
\hline Biomass & 60 & 0 & 200 & 250 \\
\hline Petroleum coke & 50 & 650 & 120 & 250 \\
\hline Fuel oil & 25 & 915 & 250 & 250 \\
\hline Limits & $\mathbf{2 0}$ & $<\mathbf{5 0 0}$ & $<\mathbf{2 5 0}$ & NA \\
\hline
\end{tabular}

The energy ( $1^{\text {st }}$ law) and exergy ( $2^{\text {nd }}$ law) analyses are effective tools used to assess the performance of energy conversion systems. Thus they can be used to identify potential improvements to the plant.

Energy efficiency, a concept defined in terms of the first law, is crucial to the utilization of energy. By the application of enthalpy data throughout the plant, one deals only with the amount of energy conversion. In this approach, heat and power are treated as equivalent forms of energy. More recently, the concept of exergy analysis has found increasingly widespread acceptance as a useful tool in the design, assessment, optimization of energy systems and, in general, quantifying the depletion of scarce resources. Thus, the degradation of energy quality is considered in the exergy analysis. Because of this key advantage, there is considerable interest in the utilization of exergy analysis for the analysis of thermal processes.

There has been no major works regarding the application of exergy analysis to brick manufacturing. None the less similar works can be found in other fields with relevance to this application, mostly in power plants [2]. Exergy analysis is a useful tool for assessing the performance of a power plant because it deals with the quality of energy and reveals the losses of useful energy in every component. Therefore, it is possible to determine where improvements will be more effective. Birnie \& Obert [3] were amongst the pioneers in the 1940 's in applying the $2^{\text {nd }}$ law to plant analysis.

Rashad and El Maihy [4] referred that most of the losses occur at the condenser though an overall efficiency above $40 \%$ was reported without significant influence of the thermal load. The authors performed a 1st and 2nd law analysis of a 1,260 MW plant at three power levels. They observed that the turbine is the major contributor to the exergy losses.

Bhattachary et al [5] performed an energy and exergy analysis of a Biomass Integrated Gasification Combined Cycle. Results show that overall thermal efficiency is $42.84 \%$ and plant exergetic efficiency is $36.86 \%$. The authors identified that the major sources of exergy destruction are the devices involved in chemical reactions and heat transfer, like gasifier, combustion chamber, heat recovery steam generator and heat exchanger.

An exergy analysis on a 4.5 MW steam power plant in Karempudi, India, has been reported by Jyothu et al [6]. The results of the exergy analysis indicate that the maximum exergy destruction occurs in the boiler with a value of $49.17 \%$ of the total exergy destruction. Therefore, the irreversibility associated with chemical reactions is the main source of exergy destruction. The thermal efficiency of the plant is rated at $18.25 \%$ and exergetic efficiency is $16.89 \%$.

Li et al [7] established a theoretical framework for the exergy analysis of a biomass boiler. The analysis was used for both the diagnosis and optimization of a biomass boiler as well as for the design of a new biomass boiler. The authors also reported that: 1) increase in biomass moisture reduces the adiabatic flame temperature, which in turn decreases the total boiler exergy efficiency; 2) an increase in excess air, both the overall boiler exergy efficiency and the adiabatic flame temperature decreased. Therefore, maintaining excess air levels as low as possible will help keep the exergy destruction at low levels; 3) increase steam temperature will reduce the exergy destruction; 4) exergy losses refer to the unburned carbon loss, radiation loss, stack gas loss and miscellaneous loss. The results of advanced exergy analysis indicate that extensive research should be concentrated on the combustion process of a biomass boiler system because the maximum exergy destruction occurs in the combustion process.

In brick manufacturing, cooking is a major operation in the process. However if biomass is used as a fuel, its drying is mandatory. Most of the work related with drying process has been focused on food related industries.

Aghbashlo et al [8] made a comprehensive review of exergy based techniques applicable in the analysis of drying processes and systems. The authors highlight the relationship between the exergy efficiency, environmental impact and sustainability. They summarize the basic equations for mass, energy and exergy balances and review the major contributions in the field, organized according to the various technologies and processes. These authors recognize that exergy method can be used to reduce inefficiencies and optimize drying systems. They also concluded that the forthcoming field of application would be the integration of exergy and economic concepts.

Chowdhury et al [9] present an energy and exergy analysis of solar drying of jackfruit leather in a solar tunnel dryer. In this process the initial moisture ( $76 \%$ on a wet basis) was reduced to $11.9 \%$. These conditions are very similar to those observed in the plant reported in this paper. The process efficiency, reflecting the loss of availability of heat in the solar drying systems, was dependent upon the solar radiation (between 100 and $600 \mathrm{Wm}^{-2}$ ) with an average exergy efficiency of approximately $42 \%$.

Akbulut and Durmus [10] discuss an experimental study concerning the convective solar dryer of mulberries. Five different mass flow rates were studied and the drying time considerably decreased when the mass flow rate increased. Also the exergy loss decreased with the increase of the mass flow rate of the drying air. The highest exergetic efficiency was recorded in the range of $44.4 \%-93.3 \%$. The data show that the exergetic efficiency of the drying chamber decreased while the energy taken from the solar collector was productively utilized.

Aziz et al [11] analyze an experimental solar dryer for food preservation. The authors assess the influence of solar reflector in the exergetic performance. Aziz et al concluded that a dryer 
with a solar reflector with same parameters and dimensions has $46 \%$ more energy available for drying, and has $60 \%$ more drying capacity than a dryer without a solar reflector. The maximum energy and exergy efficiency is obtained at full load capacity.

Azadbakht et al [12] analyzed the energy and exergy losses for the drying of eggplant using a fluidized bed dryer. The experimental tests were carried out by varying the temperature, air velocity and sample size. The authors concluded that exergy losses increased with temperature and velocity, though the effect of the temperature is much stronger. However, the size of the samples did not significantly affect exergy losses.

The exergy analysis of spray drying (skim milk powder) was investigated by Johnson and Langrish [13]. While the efficiency in mass transfer (drying) is very high (94\%) the exergetic efficiency is much lower (38\%). The authors postulate that the inevitable exergy loss method shows limitations for processes that are not exclusively thermal.

Coskun et al [14] report an energy and exergy analyses conducted to assess the performance of an industrial chips drying process. The authors found that the exergy efficiency is very low due to high energy destruction. The key to improve the efficiency is to reduce the exhaust temperature by heat recovery. It is reported that a reduction of stack gases temperature from 130 to $90{ }^{\circ} \mathrm{C}$ can improve the exergetic efficiency to $43 \%$. The plant efficiency is calculated on the exergy used for the moisture evaporation as the useful exergy.

As previously referred there is little work dedicated to the energy analysis of clay brick plants. This reflects the lack of sophistication in the industry. However the increasingly tight regulations for environmental impact and the energy efficiency (also driven by cost competitive factors) are changing the attitude in the industry towards these problems. In the face of a shift to renewable energy resources such evaluation becomes more pressing.

The present work depicts a comprehensive energetic analysis of a medium size plant that has replaced a great part of the primary energy consumption from fossil fuel to biomass. The analysis includes the operating conditions of the plant and the determination of the energy variables (set points, heat and work) through various mass and energy balances in the system.

In order to use biomass as a fuel for the brick cooking process, the biomass as to be supplied with a low moisture content. Therefore, the drying process is paramount to the feasibility of the plant. This work also includes a detailed exergetic analysis of the dryer.

\section{THE INDUSTRIAL PLANT}

The plant Amaro de Macedo S.A. operates 24 h/day, 365 days/year. Most of the production concerns the manufacturing of construction bricks. They are hollow with a standard length and height of 290 and $189 \mathrm{~mm}$ respectively. The width is variable in 5 sizes: 70, 88, 106, 146 and $220 \mathrm{~mm}$ (EN 1996-11). The operations include: extraction and storage of raw materials, preparation, drying, cooking and packaging.

All the products are manufactured by extrusion of the clay paste (mixture of clay with water at $25 \%$ humidity) made up with raw materials (including some recycled) depending on the product. The paste is squeezed through a matrix and cut at standard length.

The central part of the plant is the kiln. This is a continuous facility, $80 \mathrm{~m}$ long with a total volume of $500 \mathrm{~m}^{3}$. The load rate is $360 \mathrm{~kg} / \mathrm{m}^{3}$ which yields a total load of 180 ton. The total cooking time is $16 \mathrm{~h}$. Fig. 1 depicts the operation. The load is moved on carts through the kiln and the cooking occurs in the central region where biomass burners are located. These are supplemented with coke petroleum burners that are used to fine tune the cooking temperature and compensate the variable quality of the biomass fuel. The flue gases, before being driven out through the stack pre heat the clay load. The rapid cooling is performed by a counter current draft downstream of the burners. The hot gases are used for drying the wet bricks before being cooked. The drying chamber is a semi-continuous process where the pieces are kept for approximately $24 \mathrm{~h}$. The hot gases are driven inside the drying chamber by 2 fans ( 38 and $55 \mathrm{~kW}$ ) and the exhaust is driven by $2 \times 15 \mathrm{~kW}$ fans. The temperature of the hot gases exiting the kiln is $300{ }^{\circ} \mathrm{C}$ and are diluted with fresh air before entering the drying chamber at 125 ${ }^{\circ} \mathrm{C}$.

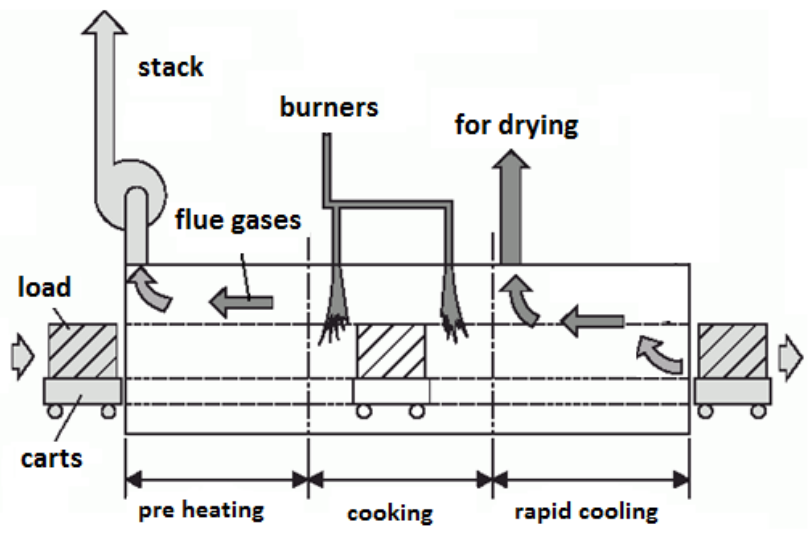

Fig. 1: Kiln layout

The biomass supplied to the kiln is sourced from a wide variety of materials. Before it is fed to the burners it is dried in a rotating dryer. This unit operates $10 \mathrm{~h} /$ day, 6 days/week. The drying capacity is 3 ton $/ \mathrm{h}$ and consumes between 400 and 500 $\mathrm{kg} / \mathrm{h}$ of biomass. The temperature varies between $600{ }^{\circ} \mathrm{C}$ (summer) and $800{ }^{\circ} \mathrm{C}$ (winter) so that the outlet temperature of the gases is $80{ }^{\circ} \mathrm{C}$ and the dried biomass is at a moisture of $10 \%$ (dry basis).

Fig. 2 shows a thermal profile of the kiln. The typical cooking temperature is above $950{ }^{\circ} \mathrm{C}$. 


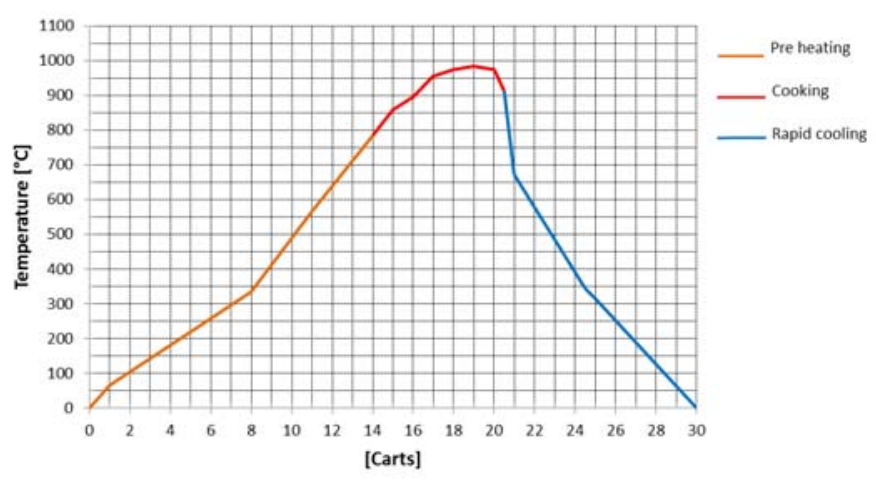

Fig. 2: Temperature profile inside the kiln

Table 2 summarizes the annual production according to the type (width) of the bricks. The total production amounted to 62,516 ton.

Table 2 - Annual production of bricks (ton)

\begin{tabular}{|c|c|c|c|c|c|}
\hline & Typ. 7 & Typ. 9 & Typ. 11 & Typ. 15 & Typ. 22 \\
\hline Production & 6,380 & 9,153 & 25,124 & 15,603 & 6,256 \\
\hline
\end{tabular}

\section{OPERATING CONDITIONS}

The analyses were carried out over a period of 4 months covering various ambient conditions. In addition to the operating conditions of the plant (mainly the energy intensive units) data was recorded for the production. This data used to assess the plant working conditions. In this paper only one case will be presented and discussed. Furthermore the energy consumption and production was obtained for a full year of production.

The flue gases were measured in situ by a portable gas analyzer Testo $350 \mathrm{XL}$, which can measure in real time the concentrations of: $\mathrm{O}_{2}, \mathrm{CO}, \mathrm{NO}, \mathrm{NO}_{2}, \mathrm{NO}_{\mathrm{x}}, \mathrm{SO}_{2}, \mathrm{H}_{2} \mathrm{~S} ; \mathrm{CO}_{2}$ is calculated off line. The samples are collected by a isokinetic probe TCR Tecora Isostack Basic. The particles were characterized by scanning electron microscopy and X-ray micro analysis (SEM).

Table 3 shows the results of the flue gases. The data is corrected for $18 \% \mathrm{O}_{2}$.

Table 3 - Flue gas analysis

\begin{tabular}{|l|c|}
\hline \multicolumn{1}{|c|}{ Parameter } & Value \\
\hline Flow rate $\left(\mathrm{m}^{3} / \mathrm{h}\right)$ & 11,484 \\
\hline Temperature $\left({ }^{\circ} \mathrm{C}\right)$ & 64 \\
\hline Moisture $\left(\mathrm{VH}_{2} \mathrm{O} / \mathrm{V}\right)$ & 4.4 \\
\hline $\mathrm{CO}\left(\mathrm{mg} / \mathrm{Nm}^{3}\right)$ & 1,795 \\
\hline $\mathrm{NO}_{2}\left(\mathrm{mg} / \mathrm{Nm}^{3}\right)$ & 68.76 \\
\hline $\mathrm{SO}_{2}\left(\mathrm{mg} / \mathrm{Nm}^{3}\right)$ & 205.7 \\
\hline Particles $\left(\mathrm{mg} / \mathrm{Nm}^{3}\right)$ & 58.3 \\
\hline
\end{tabular}

The fuel used in the test reported above was a mixture of biomass (sawdust, cork dust, bark) and petroleum coke (20\%).
The elemental analysis of each one of the biomass fuels was carried out in a TruSpec ${ }^{\circledR}$ CHN manufactured by Leco ${ }^{\circledR}$. The results for all the biomasses that are used in the plant (the type and blend depends upon the availability at the time) are summarized in Table 4.

Table 4 - Elemental analysis of biomass (in weight)

\begin{tabular}{|l|c|c|c|c|c|}
\hline \multicolumn{1}{|c|}{ Fuel } & C & H & N & S & O \\
\hline Saw dust & 55.5 & 4.87 & 0.26 & 0.01 & 38.29 \\
\hline Cork dust & 55.3 & 5.75 & 0.92 & 0.01 & 38.13 \\
\hline Olive oil bagasse & 44.8 & 5.35 & 0.38 & 0.01 & 38.13 \\
\hline Bark & 47.81 & 5.93 & 0.12 & 0.01 & 42.64 \\
\hline Wood & 49.48 & 5.38 & 0.35 & 0.01 & 43.26 \\
\hline
\end{tabular}

The ash content for each type of fuel was also measured and the results are presented in Table 5.

Table 5 - Ash content (mass \%)

\begin{tabular}{|l|c|}
\hline \multicolumn{1}{|c|}{ Fuel } & Ash \\
\hline Saw dust & 1.07 \\
\hline Cork dust & 3.95 \\
\hline Olive oil bagasse & 11.33 \\
\hline Bark & 3.49 \\
\hline Wood & 1.52 \\
\hline
\end{tabular}

Usually the company avoids the utilization of olive oil bagasse due to the high ash content.

In the two furnaces the blend of fuels is diverse. Tables 6 and 7 depict the characteristics of the fuels used in those facilities. The table includes both the Lower Heat Value (LHV) and Higher Heat Value (HHV) and the hydrogen (H) and water (W) contents.

Table 6 - Biomass LHV and HHV used in kiln

\begin{tabular}{|l|c|c|c|c|}
\hline \multicolumn{1}{|c|}{ Fuel } & $\begin{array}{c}\text { H } \\
(\mathbf{\%})\end{array}$ & $\begin{array}{c}\mathbf{W} \\
(\mathbf{\%})\end{array}$ & $\begin{array}{c}\text { LHV } \\
(\mathbf{M J} / \mathbf{k g})\end{array}$ & $\begin{array}{c}\text { HHV } \\
(\mathbf{M J} / \mathbf{k g})\end{array}$ \\
\hline Saw dust & 4.87 & 9.47 & 14.73 & 17.60 \\
\hline Cork dust & 5.75 & 12.07 & 19.26 & 23.50 \\
\hline Olive oil bagasse & 5.35 & 12.00 & 13.92 & 17.33 \\
\hline Bark & 5.33 & 13.00 & 14.67 & 18.40 \\
\hline
\end{tabular}

Table 7 - Biomass LHV and HHV used in drier

\begin{tabular}{|l|c|c|c|c|}
\hline \multicolumn{1}{|c|}{ Fuel } & $\begin{array}{c}\text { H } \\
(\mathbf{\%})\end{array}$ & $\begin{array}{c}\mathbf{W} \\
\mathbf{( \% )}\end{array}$ & $\begin{array}{c}\text { LHV } \\
(\mathbf{M J} / \mathbf{k g})\end{array}$ & $\begin{array}{c}\text { HHV } \\
(\mathbf{M J} / \mathbf{k g})\end{array}$ \\
\hline Saw dust & 4.87 & 42.76 & 8.42 & 17.60 \\
\hline Cork dust & 5.75 & 42.76 & 11.68 & 23.50 \\
\hline Olive oil bagasse & 5.35 & 42.76 & 8.20 & 17.33 \\
\hline Bark & 5.33 & 42.76 & 8.82 & 18.40 \\
\hline Wood & 5.38 & 42.76 & 9.40 & 19.42 \\
\hline
\end{tabular}

It is observed that the biomass drying is necessary to operate the cooking kiln; otherwise the necessary operating temperature could not be reached. 


\section{ENERGY ANALYSIS}

Based on the energy records for a full year it was estimated that the annual energy consumption amounts to 2,808.8 toe. Fig. 3 depicts the split between the various sources. Diesel accounts for small machinery such as fork lifts used in the plant.

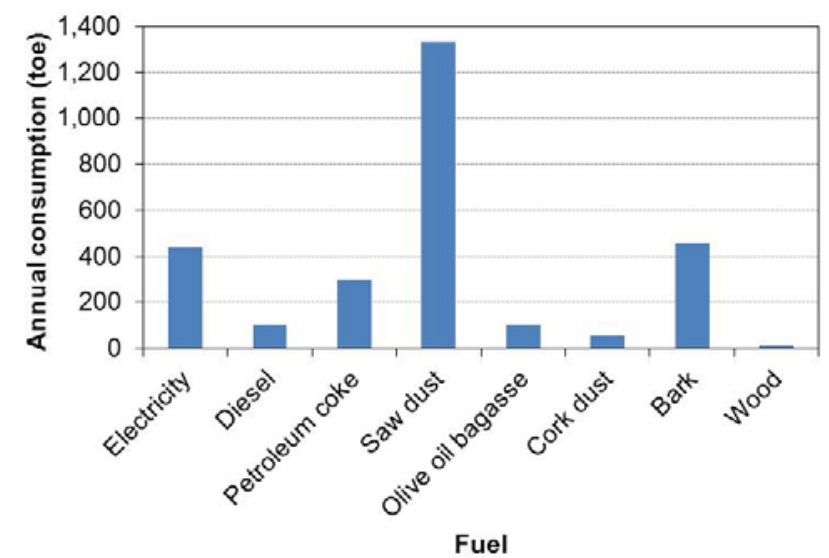

Fig. 3: Annual energy consumption

The relevance of switching to biomass is observed as it accounts for $70 \%$ of the total energy consumption in the plant. Regarding the cooking kiln the biomass represents 1,645.8 toe out of a total of $1,946.3$ toe $(84.5 \%)$. Taking into account the blend of biomass fuels, this option displaces a total of 763.8 toe of petroleum coke and avoids the release of 3,117.9 ton $\mathrm{CO}_{2}$ per annum.

The usage of energy in the various operations of the plant is depicted in Fig. 4 on a percentage basis.

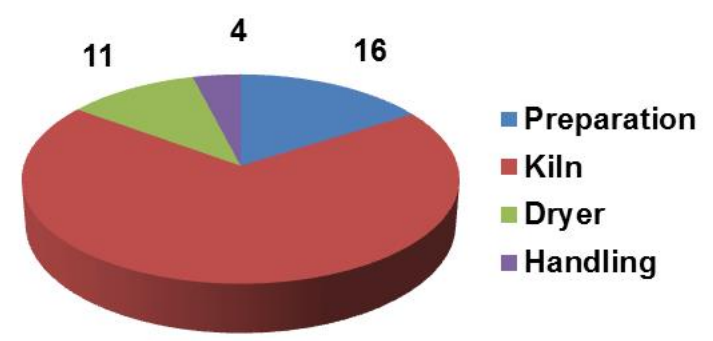

69

\section{Fig. 4: Energy consumption in the plant (in \%)}

Based upon the monthly production, the energy intensity ratio can be calculated, as depicted in Fig. 5.

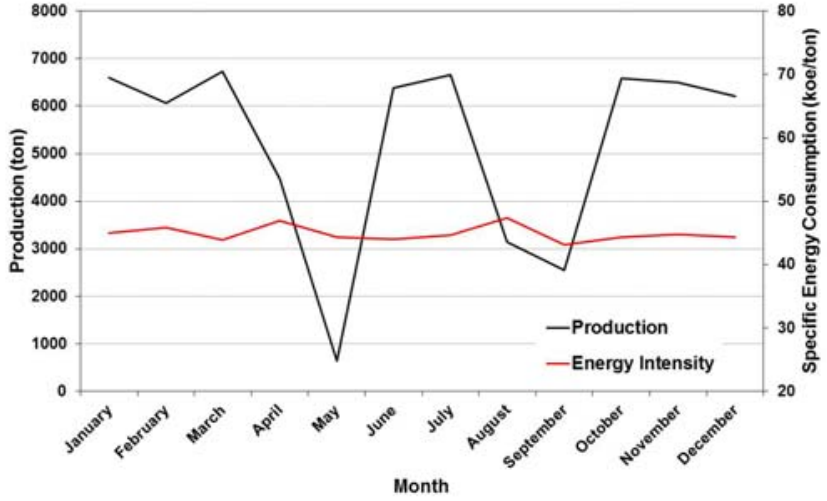

Fig. 5: Monthly variation of the energy intensity

The data shows that, despite the wide variation on the production throughout the year (with implications on the thermal load of the dryer and the kiln), the energy intensity of the plant if approximately constant with an average value of 44 koe/ton.

Because types of bricks cover a wide range of sizes, and their relative production varies throughout the year it is of interest to normalize the production into an equivalent product.

The shape of the various bricks includes longitudinal holes than enhance the total surface area. As the major physical processes include heat and mass transfer it is argued that the production of the various bricks could be normalized by the mass/surface area of each one. Taking the type 7 (the lightest at $3.5 \mathrm{~kg}$ each) as the reference, the proposed ratio implies that the energy consumption for the others should be (Table 8):

Table 8 - Annual production of bricks (ton)

\begin{tabular}{|l|c|c|c|c|c|}
\hline & Typ. . & Typ. 9 & Typ. 11 & Typ. 15 & Typ. 22 \\
\hline Production & 6,380 & 9,153 & 25,124 & 15,603 & 6,256 \\
\hline Ratio & 1.00 & 1.12 & 1.15 & 1.33 & 1.63 \\
\hline Eq. Prod. & 6,380 & 10,271 & 28,990 & 20,683 & 10,188 \\
\hline
\end{tabular}

Based on the normalized production the energy intensity would be $27.45 \mathrm{koe} /$ ton $_{\text {Type }} 7$.

A detailed analysis of the biomass dryer has been carried out. A mixture of biomass is supplied (1) to the furnace along the combustion air and that required for dilution (2). The hot gases (4) at a temperature of $600{ }^{\circ} \mathrm{C}$ are mixed with the biomass fed by the conveyer (5). The mixture is separated in two stages (settling chamber and cyclone) before being released to the atmosphere (8). The dried biomass is removed in (7). Heat losses (by radiation and convection) are expected in the dryer and furnace. (3) and (6) are heat losses to the environment. The inlet/outlet fluxes are depicted in Fig. 6. 


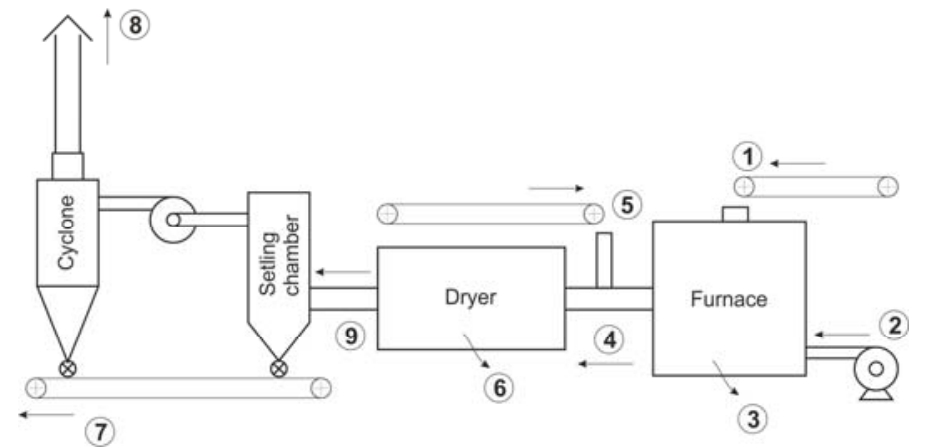

Fig. 6: Schematic view of the biomass dryer

The main parameters are summarized in Table 9.

Table 9 - Operating parameters of the dryer

\begin{tabular}{|l|c|c|c|c|c|}
\hline & $\mathbf{1}$ & $\mathbf{2}$ & $\mathbf{5}$ & $\mathbf{7}$ & $\mathbf{8}$ \\
\hline $\mathrm{T}\left({ }^{\circ} \mathrm{C}\right)$ & 25 & 25 & 25 & 43.3 & 64 \\
\hline$\dot{m}(\mathrm{~kg} / \mathrm{h})$ & & 247 & $1,544.8$ & $1,544.8$ & $7,411.8$ \\
\hline $\begin{array}{l}\mathrm{Moisture} \\
\left(\mathrm{kgH}_{2} \mathrm{O} / \mathrm{kg}\right)\end{array}$ & 0.008 & 0.75 & 0.75 & 0.10 & 0.149 \\
\hline
\end{tabular}

The mass flow rate of fuel (blend of biomass) was estimated through average consumption assuming $10 \mathrm{hr} /$ day and 6 days/week operation. The water content (on a dry basis was measured from samples of biomass as described in the previous section. The results are shown in Table 10 for both a dry and wet basis.

Table 10 - Operating parameters of the dryer

\begin{tabular}{|l|c|c|}
\hline & $\mathrm{kg} / \mathrm{h}($ dry) & $\mathrm{kg} / \mathrm{h}$ (wet) \\
\hline Saw dust & 167.5 & 292.6 \\
\hline Cork dust & 8.6 & 15.0 \\
\hline Olive oil bagasse & 5.0 & 8.7 \\
\hline Bark & 55.7 & 97.3 \\
\hline Wood & 11.8 & 20.6 \\
\hline
\end{tabular}

The outlet temperature of the dryer (9) is the operating set point, $80^{\circ} \mathrm{C}$. The heat losses in the furnace and the dryer were calculated by measuring the surface temperature $\left(72.4^{\circ} \mathrm{C}\right.$ at the furnace; $59.4{ }^{\circ} \mathrm{C}$ at the dryer) and calculating the radiative losses using an emissivity of 0.63 (refractory material in the furnace) and 0.74 (steel in the dryer). The convection coefficients were estimated for the natural convection regime.

Using the heat value of the biomass blend the heat load of the furnace is $4.5 \mathrm{MJ} / \mathrm{h}$. Also considering the stoichiometric ratio for the fuel blend (taking into consideration the elemental analysis) and assuming an excess air typical for biomass combustion, the combustion air was calculated.

The final energy balance for the dryer is depicted in Fig. 7.

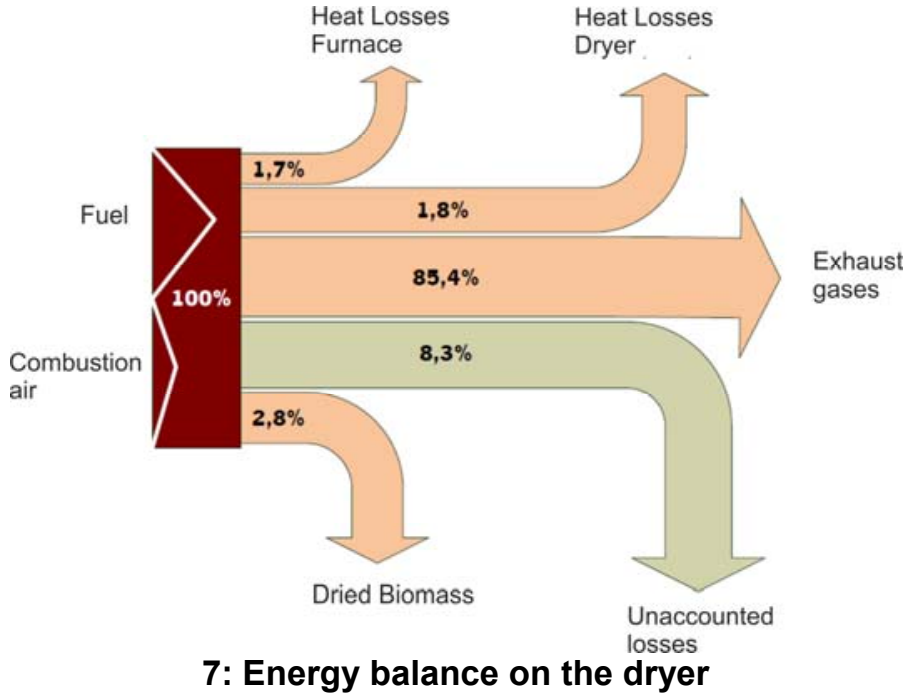

Based on the understanding of the plant operation the unaccounted losses are mostly associated with leakages that occur with the biomass supply.

Taking into account the heat load of the furnace $\dot{Q}_{\mathrm{f}}$ one can calculate the specific consumption of energy in drying, $q_{\text {dry }}$, through:

$$
q_{\text {dry }}=\frac{\dot{Q}_{\mathrm{f}}}{\dot{m}_{w}}
$$

Taking into consideration the total flux of moisture in the biomass $(185 \mathrm{~kg} / \mathrm{hr})$, this results in a value of $3,873 \mathrm{~kJ} / \mathrm{kg}_{\text {water }}$. This is considerably higher than the standard enthalpy of vaporization for water at $25^{\circ} \mathrm{C}(2,546.5 \mathrm{~kJ} / \mathrm{kg})$. Inefficiencies in the plant and stack losses account for an overall efficiency of $65 \%$.

\section{EXERGY ANALYSIS}

The exergetic analysis to the dryer was performed by splitting the control volume into three regions: the furnace, the dryer and the separation. For each one the exergy balance can be written as [15-17]:

$$
\dot{E}_{\text {in }}+\dot{E}^{Q}=\dot{E}_{\text {out }}+\dot{W}+\dot{I}
$$

The terms with the subscripts in and out denote, respectively, the inlet and outlet exergy associated to the mass flows. The term $\dot{E}^{Q}$ represents the positive cross boundary thermal exergy while $\dot{W}$ is the work exchanged through the boundaries. The term $\dot{I}$ represents the exergy rate of destruction or irreversibility rate at each system or sub-system.

For the combustion chamber, furnace, the exergy balance becomes

$$
\begin{aligned}
& \dot{I}_{F}=\left(\dot{E}_{\mathrm{ph}}\right)_{1}+\left(\dot{E}_{0}\right)_{1}+\left(\dot{E}_{\mathrm{ph}}\right)_{2}+\left(\dot{E}_{0}\right)_{2} \\
& -\left(\dot{E}_{\mathrm{ph}}\right)_{4}-\left(\dot{E}_{0}\right)_{4}+\dot{W}_{F}
\end{aligned}
$$


being $\left(\dot{E}_{\mathrm{ph}}\right)_{2}=\left(\dot{E}_{0}\right)_{2}=\left(\dot{E}_{\mathrm{ph}}\right)_{1}=0$. The exergy associated to the thermal losses ("3" in Fig. 6) is zero. $\dot{W}_{F}$ stands for the power of the air supply ventilator and the motors for the feeding mechanisms. The subscripts in Eq. (3) refer to the positions identified in Table 9 and Fig. 6.

The physical exergy, $\dot{E}_{\mathrm{ph}}$, is calculated by:

$$
\dot{E}_{\mathrm{ph}}=\dot{m}\left[c_{p}\left(T-T_{0}\right)-T_{0}\left(c_{p} \ln \frac{T}{T_{0}}-\bar{R} \ln \frac{p}{p_{0}}\right)\right]
$$

assuming the flue gases as an Ideal Gas. The chemical exergy for the flue gases is calculated as a mixture through:

$$
\left(\dot{E}_{0}\right)_{4}=\frac{\dot{m}}{\bar{M}}\left(\sum x_{i} \varepsilon_{i}+\tilde{R} T_{0} \sum x_{i} \ln x_{i}\right)
$$

being $x_{i}$ the mole fraction of the $i$ component. The composition results from the stoichiometric reaction of the biomass and the excess air referred above:

$$
\begin{aligned}
& a \mathrm{C}+b \mathrm{H}+c \mathrm{O}+d \mathrm{~N}+f \mathrm{~S}+x(1+e)\left(\mathrm{O}_{2}+3.76 \mathrm{~N}_{2}\right) \Rightarrow \\
& a \mathrm{CO}_{2}+\left(\frac{b}{2}+w\right) \mathrm{H}_{2} \mathrm{O}+f \mathrm{SO}_{2}+y \mathrm{~N}_{2}+e \cdot x \mathrm{O}_{2}
\end{aligned}
$$

As for the chemical exergy, for solid fuels the relationship is applicable:

$$
\left(\dot{E}_{0}\right)_{\mathrm{f}}=\left(\dot{E}_{0}\right)_{1}=L H V \cdot \phi
$$

The factor $\varphi$ depends upon the chemical composition of the fuel

$$
\varphi=\frac{1.0438+0.1882 \frac{h}{c}-0.2509\left(1+0.7256 \frac{h}{c}\right)+0.0383 \frac{n}{c}}{1-0.3035 \frac{o}{c}}
$$

In equation (8) $h, c, n$ and $o$ refer to the mass fractions of Hydrogen, Carbon, Nitrogen and Oxygen in the biomass. $\dot{W}_{F}$ is $6.5 \mathrm{~kW}$.

For the dryer, the irreversibility is calculated through:

$$
\dot{I}_{D}=\left(\dot{E}_{\mathrm{ph}}\right)_{4}+\left(\dot{E}_{0}\right)_{4}+\left(\dot{E}_{\mathrm{ph}}\right)_{5}+\left(\dot{E}_{0}\right)_{5}-\left(\dot{E}_{\mathrm{ph}}\right)_{9}-\left(\dot{E}_{0}\right)_{9}
$$

with $\left(\dot{E}_{\mathrm{ph}}\right)_{5}=0$. The mechanical power is neglected. The exergy associated thermal losses (stream 6) is zero. Because there are no species conversion, the chemical exergy changes cancel out and

$$
\dot{I}_{D}=\left(\dot{E}_{\mathrm{ph}}\right)_{4}-\left(\dot{E}_{\mathrm{ph}}\right)_{\text {out }}
$$

For the separation, the irreversibility is calculated through:

$$
\begin{aligned}
& \dot{I}_{S}=\left(\dot{E}_{\mathrm{ph}}\right)_{9}+\left(\dot{E}_{0}\right)_{9}-\left(\dot{E}_{\mathrm{ph}}\right)_{7}-\left(\dot{E}_{0}\right)_{7} \\
& -\left(\dot{E}_{\mathrm{ph}}\right)_{8}-\left(\dot{E}_{0}\right)_{8}+\dot{W}_{S}
\end{aligned}
$$

Considering the mixing process at the stack outlet, the flue gases will come into equilibrium with the environment and for both physical and chemical exergy the conditions are those of the reference state (zero exergy). Because there is no species conversion, the exergy balance becomes:

$$
\dot{I}_{S}=\left(\dot{E}_{\mathrm{ph}}\right)_{9}-\left(\dot{E}_{\mathrm{ph}}\right)_{7}+\dot{W}_{S}
$$

$\dot{W}_{S}$ is all the mechanical power (mostly the ventilator) which amounts to $5 \mathrm{~kW}$.

In the calculations the mechanical power (ventilator and feeding belts was neglected. The exergy of the biomass fuel is calculated at 1,519 kW. For each region the exergetic efficiency can be calculated through:

$$
\psi=\frac{\dot{E}_{\text {out }}}{\dot{E}_{\text {in }}}=1-\frac{\dot{I}}{\dot{E}_{\text {in }}}
$$

The final results are summarized in Table 11.

Table 11 - Irreversibilities in the dryer

\begin{tabular}{|l|c|c|c|}
\hline & $\begin{array}{c}\text { Irreversibility } \\
(\mathrm{kW})\end{array}$ & $\dot{E}_{\text {in }}(\mathrm{kW})$ & $\psi$ \\
\hline Furnace & 969.5 & 1,519 & 36.2 \\
\hline Dryer & 531.4 & 549.5 & 3.3 \\
\hline Separation & 8 & 18.1 & 55.8 \\
\hline
\end{tabular}

The drying exergetic efficiency can be determined by:

$$
\psi_{\text {dry }}=\frac{\left(\dot{m}_{w}\right)_{\text {ev }}\left(\dot{E}_{\text {water vapor }}-\dot{E}_{\text {water }}\right)}{\dot{E}_{f}}
$$

which gives $\psi_{\text {dry }}=3.4 \%$.

The results show a very low exergetic efficiency of the plant, particularly at the drying process. In fact, by using a fuel there is a very high energy degradation. In solar based processes the efficiency is higher as the energy degradation is lower.

\section{CONCLUSIONS}

The present paper develops an energy and exergy analysis on a red clay brick manufacturing plant. Data concerning the plant operation was obtained periodically over a period of four months.

The plant uses up to $80 \%$ of biomass as the energy source for its cooking kiln; the remaining being petroleum coke. The various sources of biomass were characterized for the elemental analysis, heat value (high and low) ash content and moisture. Because of its source, handling and storage this presents a very high ratio. Therefore a rotating dryer is part of the plant. This uses also biomass as fuel to bring the moisture of the biomass used in the kiln down to approximately $10 \%$.

Although the plant load varies throughout the year and there are typically 5 types of bricks in production, the energy intensity of the plant is approximately constant at an average 44 koe/ton, which is within the practice in the industry. A method is proposed to normalize the production of the various types of 
bricks into an equivalent type 7 . The use of biomass displaces the emission of $3,117.9$ ton $\mathrm{CO}_{2}$ per annum.

The operation of the biomass dryer was analyzed in terms of energy utilization and energy degradation. The specific consumption of energy in drying is $3,873 \mathrm{~kJ} / \mathrm{kg}_{\text {water }}$.

The exergy analysis revealed that the furnace has the highest irreversibility although the rotating dryer has the lowest exergetic efficiency. The drying exergetic efficiency is $3.4 \%$. The use of solar energy is drying would improve the overall efficiency.

\section{NOMENCLATURE}

$\begin{array}{ll}c_{p} & \text { Specific Heat, } \mathrm{kJ} / \mathrm{kgK} \\ e & \text { Excess air } \\ \dot{E} & \text { Rate of Exergy flow, } \mathrm{kW} \\ h & \text { Enthalpy, } \mathrm{kJ} / \mathrm{kg} \\ H H V & \text { High Heating Value, } \mathrm{kJ} / \mathrm{kg} \\ \dot{I}_{S} & \text { Irreversibility, } \mathrm{kW} \\ \mathrm{koe} & \text { kg of equivalent oil } \\ L H V & \text { Low Heating Value, } \mathrm{kJ} / \mathrm{kg} \\ \dot{m} & \text { Mass flow rate, } \mathrm{kg} / \mathrm{s} \\ M & \text { Molar mass, } \mathrm{kg} / \mathrm{kmol} \\ p & \text { Pressure, bar } \\ \dot{Q} & \text { Thermal Power, } \mathrm{kW} \\ \bar{R} & \text { Gas Constant, } \mathrm{J} / \mathrm{kgK} \\ \widetilde{R} & \text { Ideal Gases Constant, } \mathrm{J} / \mathrm{moleK} \\ \text { toe } & \text { ton of equivalent oil } \\ T & \text { Temperature, } \mathrm{K} \\ T_{0} & \text { Reference Ambient Temperature, } \mathrm{K} \\ \dot{W} & \text { Work, kW } \\ x & \text { volumetric fraction }\end{array}$

\section{Greek symbols}

$\begin{array}{ll}\varepsilon & \text { Chemical exergy of the substance, } \mathrm{kJ} / \mathrm{mol} \\ \eta & \text { Efficiency } \\ \psi & \text { Exergetic Efficiency }\end{array}$

\begin{tabular}{ll}
\multicolumn{2}{l}{ Subscripts } \\
$d r y$ & drying \\
$f$ & fuel \\
in & inlet \\
$l v$ & liquid-vapor \\
$o$ & chemical \\
out & outlet \\
$p$ & combustion products \\
$p h$ & physical exergy \\
$w$ & water
\end{tabular}

\section{Superscripts}

$\begin{array}{ll}Q & \text { Thermal component of exergy } \\ W & \text { Work component of exergy }\end{array}$

\section{ACKNOWLEDGEMENTS}

This work was financed by FCT, under the Strategic Project UID/SEM/04077/2013. The authors acknowledge the contribution of Amaro de Macedo S.A., for providing access to the plant.

\section{REFERENCES}

[1] APICER; CTCV, 2008, "Caracterização do subsector da Indústria cerâmica estrutural em Portugal", pp. 11-44, 2008 (in Portuguese).

[2] H. Feng, L. Chen, F. Sun, "Exergoeconomic optimal performance of an irreversible closed Brayton cycle combined cooling, heating and power plant", Applied Mathematical Modelling. 35 (2011) 4661-4673.

[3] C. Birnie, E. F. Obert. "Evaluation and location of losses in a 60 MW power station", Proc. Midwest Power Conf., vol. 11, pp. 187-193, Exergy, Power Engineering, (1949).

[4] A. Rashad and A. El Maihy. "Energy and Exergy Analysis of a Steam Power Plant in Egypt"; 13th International Conference on Aerospace Sciences \& Aviation Technology (2009); Paper: ASAT-13-TH-02.

[5] A. Bhattachary, D. Manna, B. Paul, A. Datta. "Biomass integrated gasification combined cycle power generation with supplementary biomass firing: Energy and exergy based performance analysis", Energy 36 (2011) 2599-2610.

[6] R. Jyothu. Naik, B. L.V. S. Gupta, G. S. Sharma. "Exergy Analysis of 4.5MW Biomass Based Steam Power Plant", Journal of Humanities and Social Science, Volume 1, Issue 1 (July-August 2012).

[7] C. Li, C. Gillum, K. Toupin, B. Donalson. "Biomass boiler energy conversion system analysis with the aid of exergy-based methods", Energy Conversion and Management 103 (2015) 665-673.

[8] Aghbashlo, M; Mobli, H; Rafiee, S and Madadlou, A. "A review on exergy analysis of drying processes and systems", Renewable and Sustainable Energy Reviews, Volume 22, (2013), pp: 1-22.

[9] Chowdhury, M; Bala, B; and Haque, M. "Energy and exergy analysis of the solar drying of jackfruit leather", Biosystems Engineering, 110 (2011) pp. 222-229.

[10] Akbulut, A and Durmus, A. "Energy and exergy analyses of thin layer drying of mulberry in a forced solar dryer", Energy, 35 (2010), pp. 1754-1763.

[11] Aziz, A; Rehman, S and Rehman, S. "Exergy Analysis of Solar Cabinet Dryer and Evaluate the Performance Enhancement of Solar Cabinet Dryer by Addition of Solar Reflectors", Int J Renewable Energy Research, Vol 6, n. 4, (2016).

[12] Azadbakht, M; Torshizi, M; Ziaratban, A and Aghili, H. "Energy and exergy analyses during eggplant drying in a fluidized bed dryer", CIGR Journal, Vol. 19, No. 3 (2017).

[13] Johnson, P and Langrish, T. "Exergy analysis of a spray dryer: Methods and interpretations, Energy and Environmental Analysis", Drying Technology, VOL. 36, NO. 5, (2018), pp. 578-596.

[14] Coskun, C; Bayraktar, M; Oktay, Z and Dincer, I. "Energy and exergy analyses of an industrial wood 
chips drying process" International Journal of LowCarbon Technologies, 4, (2009), p. 224-229.

[15] T.J. Kotas. "Exergy Analysis of Simple processes, in: The Exergy Method of Thermal Plant Analysis", Anchor Brendon Ldt, (1985): pp. 99-150.

[16] G. Tsatsaronis. "Thermoeconomic Analysis and optimization of energy systems", Progress in Energy and Combustion Science. 19 (1993); 227-257.

[17] I. Dincer. "Exergy: energy, environment and sustainable development", 1st ed. Oxford: Elsevier, (2007). 